Polyethersulfone (PES, Solvay Advanced Polymer, L.L.C., USA), n-methyl-2-pyrrolidone (NMP, $99 \%$, Aladdin, China) and polyethylene glycol 400 (PEG MW = $400 \mathrm{~g} \cdot \mathrm{mol}^{-1}$, Fuchen, China) were used to prepare PES dope for membrane substrate fabrication. MPD (99\%, Aladdin, China), TMC (98\%, Micxy, China) and n-hexane (95\%, Aladdin, China) were deployed to synthesize the PA layer of membrane. $\mathrm{Fe}\left(\mathrm{NO}_{3}\right)_{3} \cdot 9 \mathrm{H}_{2} \mathrm{O}$ (98 \%, Aladdin, China), $\mathrm{Cu}\left(\mathrm{NO}_{3}\right)_{2} \cdot 6 \mathrm{H}_{2} \mathrm{O}(99 \%$, Aladdin, China $)$ and $\mathrm{Co}\left(\mathrm{NO}_{3}\right)_{2} \cdot 3 \mathrm{H}_{2} \mathrm{O}(98 \%$, Aladdin, China $)$ are the sources of metal ions. $\mathrm{NaCl}(99.5 \%$, Xilong Scientific, China) was used to study membrane used throughout the experiments. 
A pristine FO membrane consisting of a porous PES substrate and a dense PA layer was prepared prior to membrane modification. The PES substrate was fabricated first from a dope solution containing PES (15.0 wt \%), PEG 400 (42.5 wt \%) and NMP (42.5 wt \%) by a non-solvent induced phase inversion approach. ${ }^{1}$ A dense PA layer was then formed on the top of PES substrate via interfacial polymerization between MPD and TMC using an established method. ${ }^{1,2}$ A TFC FO membrane was thus obtained.

\section{Membrane Characterizations.}

The functional groups were identified by fourier transform infrared spectroscopy (FTIR, Nicolet iS10, Thermo Fisher Scientific, USA). Elements on membrane surface were determined by X-ray photoelectron spectroscopy (XPS, ESCALAB 250, Thermo Scientific, USA) using Mg/Al Dual Anode Hel/Hell ultraviolet source. Membrane surface potentials were analyzed using a zeta potential analyzer (NanoBrook Omni, Brookhaven, USA). All measurements were conducted in a background electrolyte solution containing $1.0 \mathrm{mM} \mathrm{KCl}$ in neutral conditions at room temperature, coupled with a surface zeta potential electrode. Membrane hydrophilicity was evaluated by measuring the water contact angle using a contact angle goniometry (Precise Test, China). The results presented here are the average of at least six measurements. 
The morphology and topology of both the substrate and FO membrane were studied respectively by using a field emission scanning electron microscope (FESEM, Nova NanoSEM 230, FEI, USA) and an atomic force microscopy (AFM, Agilent, USA). Membrane samples had been freeze-dried using a freeze-dryer (FDU-1200, EYELA, Japan) at $-50^{\circ} \mathrm{C}$ for $48 \mathrm{~h}$ prior to experiments. Structural parameters including mean pore size, pore size distribution and MWCO were analyzed through measurements performed on a dead-end permeation cell by a solute separation approach. ${ }^{1}$

\section{Membrane Separation Properties.}

The intrinsic membrane separation properties including water permeability, salt rejection and salt permeability coefficient were characterized through experiments conducted in a dead-end permeation cell under the RO mode. The water permeability coefficient $A$ $\left(\mathrm{L} \cdot \mathrm{m}^{-2} \cdot \mathrm{h}^{-1} \cdot \mathrm{bar}^{-1}\right.$, denoted as $\left.\mathrm{LMH} \cdot \mathrm{bar}^{-1}\right)$ was obtained from the pure water permeation flux with DI water as the feed under a 2.0-bar trans-membrane pressure. $A$ was then determined by the equation below:

$$
A=\frac{\Delta V}{A_{m} \times \Delta t \times \Delta P}
$$

where $\Delta V(\mathrm{~L})$ is the water permeation volume in the experimental interval of $\Delta t(\mathrm{~h}), A_{m}\left(\mathrm{~m}^{2}\right)$ is the effective membrane area in RO test, and $\Delta P$ (bar) is the applied pressure.

The salt rejection $\left(R_{s}\right)$ was obtained from the measurements with a $500 \mathrm{ppm} \mathrm{NaCl}$ solution as the feed under a 2.0-bar applied pressure. The salt rejection was calculated from equation (2) based on the permeate $\left(C_{p}, \mathrm{~mol} \cdot \mathrm{L}^{-1}\right)$ and feed concentrations $\left(C_{f}, \mathrm{~mol} \cdot \mathrm{L}^{-1}\right):^{3}$ 


$$
R_{s}=\left(1-\frac{C_{p}}{C_{f}}\right) \times 100 \%
$$

The salt permeability coefficient $B(\mathrm{LMH})$ was then acquired based on the solution-diffusion theory presented in equation (3): ${ }^{4}$

$$
B=A \frac{\left(1-R_{s}\right)(\Delta P-\Delta \pi)}{R_{s}}
$$

where $\Delta \pi$ (bar) is the osmotic pressure differential across the membrane.

\section{FO Experiments.}

A bench-scale FO system (Suzhou Faith \& Hope Membrane Technology Co. Ltd.) was used to evaluate the membrane performance. The FO system has an effective membrane area of $4.5 \mathrm{~cm}^{2}$. Feed and draw solutions flowed counter-currently at $1.3 \mathrm{~cm} \cdot \mathrm{s}^{-1}$ along the rectangular channels on each side of a permeation cell. $\mathrm{MgCl}_{2}$ served as the $\mathrm{FO}$ draw solute. Either DI water or pharmaceutical-containing water was used as the feed solution. Experiments under pressure retarded osmosis (PRO, where the active layer faces the draw solution) mode and FO (where the active layer faces the feed solution) mode were both conducted at $23 \pm 2{ }^{\circ} \mathrm{C}$. Membrane water flux $J_{w}(\mathrm{LMH})$ was obtained from equation (4):

$$
J_{w}=\frac{\Delta V}{A_{m} \times \Delta t}
$$

where $\Delta V(\mathrm{~L})$ is the volume difference of the feed solution before and after experiments, $A_{m}$ $\left(\mathrm{m}^{2}\right)$ is the effective membrane area, and $\Delta t(\mathrm{~h})$ is the experimental interval.

The reverse salt flux $J_{s}\left(\mathrm{~g} \cdot \mathrm{m}^{-2} \cdot \mathrm{h}^{-1}\right.$, denoted as $\left.\mathrm{gMH}\right)$ was calculated by the following equation: 
where $C_{0}\left(\mathrm{~g} \cdot \mathrm{L}^{-1}\right)$ and $C_{t}\left(\mathrm{~g} \cdot \mathrm{L}^{-1}\right), V_{0}(\mathrm{~L})$ and $V_{t}(\mathrm{~L})$ are the respective initial and final salt concentration and volume of feed solution. The salt concentration in the feed water was converted from the conductivity values based on a standard curve built from the relationship between known concentrations and conductivities. All the reported data are the average of at least three parallel measurements.

Experiments of wastewater reclamation and pharmaceutical enrichment were carried out under the FO mode with solutions containing TMP or SMX as the feeds and a $2.0 \mathrm{M} \mathrm{MgCl}_{2}$ solution as the draw solution. TMP or SMX permeating to the draw solution side during FO processes was detected by measuring the absorptions with an Ultraviolet/Visible Spectrophotometer (UV-1780, Shimadzu, Japan) at their maximum absorption wavelength. The pharmaceutical concentration in draw solution was then obtained from the standard curve built based on the relationship between the UV absorption and known pharmaceutical concentrations. The real concentration of pharmaceuticals diffusing to the draw solution can then be obtained from equation (6):

$$
C_{s(t)}=\frac{C_{d(t)} \times V_{d(t)}}{V_{f(t)}}
$$

where $V_{f(t)}(\mathrm{L})$ and $V_{d(t)}(\mathrm{L})$ are the respective feed and draw solution volumes at time of $t, C_{d(t)}$ $(\mathrm{ppm})$ is the concentration of TMP or SMX in draw solution at time of $t$. The rejection of TMP or SMX in the FO process is then calculated by the equation below: 5

$$
R=\left(1-\frac{C_{s(t)}}{C_{f(t)}}\right) \times 100 \%
$$

where $C_{f(t)}(\mathrm{ppm})$ is the concentration of the TMP or SMX in the feed at time of $t$. 
Table S1. Comparison of $\mathrm{FO}$ performances for $\mathrm{Fe}^{3+}$ membrane and other reported membranes.

\begin{tabular}{|c|c|c|c|c|c|c|}
\hline \multirow[t]{2}{*}{ FO membrane } & \multicolumn{2}{|c|}{$\begin{array}{c}\text { Water flux } \\
\text { (LMH) }\end{array}$} & \multicolumn{2}{|c|}{$\mathbf{J s} / \mathbf{J w}(\mathbf{g} / \mathbf{L})$} & \multirow{2}{*}{$\begin{array}{c}\text { Draw } \\
\text { solution } \\
\text { (M) }\end{array}$} & \multirow[t]{2}{*}{ Refs. } \\
\hline & FO & PRO & FO & PRO & & \\
\hline \multirow{4}{*}{$\mathrm{Fe}^{3+}$ membrane } & 14.0 & 16.7 & 0.034 & 0.040 & 0.5 & \multirow{4}{*}{$\begin{array}{l}\text { This } \\
\text { work }\end{array}$} \\
\hline & 18.0 & 24.7 & 0.043 & 0.030 & 1.0 & \\
\hline & 22.7 & 30.0 & 0.038 & 0.027 & 1.5 & \\
\hline & 26.7 & 36.1 & 0.032 & 0.025 & 2.0 & \\
\hline $\mathrm{P}-2 \mathrm{SO}_{3}-2 \mathrm{NH}_{2}$ & 12.0 & 14.7 & 0.101 & 0.089 & 0.5 & {$[6]$} \\
\hline MWCNTs/PEI/PAI & 12.5 & 11.4 & 0.340 & 2.667 & 0.5 & {$[7]$} \\
\hline 1\#LBL-PAN & 27.7 & 13.2 & 2.268 & 11.684 & 1.0 & [8] \\
\hline TFN-0.05/CNTs/PSF & 7.9 & 12.5 & 0.215 & 0.120 & 2.0 & [9] \\
\hline $\begin{array}{c}\text { TFN-0.05/GQDs/PA } \\
\mathrm{N}\end{array}$ & 12.9 & - & 0.109 & - & 0.5 & {$[10]$} \\
\hline Zein/PEI/PES & 21.5 & 31.0 & 0.242 & 0.265 & 2.0 & {$[11]$} \\
\hline
\end{tabular}

Note: DI water and $\mathrm{MgCl}_{2}$ as the respective feed and draw solutions. $\mathrm{P}-2 \mathrm{SO}_{3}-2 \mathrm{NH}_{2}$ : 1,4-bis(3-aminopropyl) piperazine propanesulfonate, MWCNTs: multiwall carbon nanotubes, PEI: polyethyleneimine, PAI: poly(amid-imide), LBL: layer by layer, PAN: polyacrylonitrile, CNTs: carbon nanotubes, PSF: polysulfone, GQDs: graphene quantum dots.

Table S2. Physicochemical properties of the pharmaceuticals used in this study.

\begin{tabular}{|c|c|c|}
\hline Pharmaceutical & SMX & TMP \\
\hline \multicolumn{3}{|l|}{ Structure } \\
\hline MW. $\left(\mathrm{g} \cdot \mathrm{mol}^{-1}\right)$ & 253.28 & 290.32 \\
\hline Charge $(\mathrm{pH}=7)$ & negative & positive \\
\hline pKa & $1.4 ; 5.8$ & 7.2 \\
\hline Water solubility $\left(\mathbf{m g} \cdot \mathbf{L}^{-1}\right)$ & 610 & 400 \\
\hline Reference & {$[12,13]$} & {$[12,13]$} \\
\hline
\end{tabular}




\section{REFERENCES}

132

(1) Yang, Q.; Lau, C. H.; Ge, Q. Novel ionic grafts that enhance arsenic removal via forward osmosis. ACS Appl. Mater. Interfaces 2019, 11, 17828-17835.

(2) Shen, L.; Zuo, J.; Wang, Y. Tris (2-aminoethyl) Amine in-situ modified thin-film composite membranes for forward osmosis applications. J. Membr. Sci. 2017, 537, 186-201.

(3) Zhang, Y.; Yang, L.; Pramoda, K. P.; Gai, W.; Zhang, S. Highly permeable and fouling-resistant hollow fiber membranes for reverse osmosis. Chem. Eng. Sci. 2019, 207, 903-910.

(4) Zhang, Y.; Sun, H.; Sadam, H.; Liu, Y.; Shao, L. Supramolecular chemistry assisted construction of ultra-stable solvent-resistant membranes for angstrom-sized molecular separation. Chem. Eng. J. 2019, 371, 535-543.

(5) Zheng, L.; Price, W. E.; McDonald, J.; Khan, S. J.; Fujioka, T.; Nghiem, L. D. New insights into the relationship between draw solution chemistry and trace organic rejection by forward osmosis. J. Membr. Sci. 2019, 587, 117184.

(6) Li, P.; Ge, Q. Membrane surface engineering with bifunctional zwitterions for efficient oil-water separation. ACS appl. Mater. Interfaces 2019, 11, 31328-31337.

(7) Goh, K.; Setiawan, L.; Wei, L.; Jiang, W.; Wang, R.; Chen, Y. Fabrication of novel functionalized multi-walled carbon nanotube immobilized hollow fiber membranes for enhanced performance in forward osmosis process. J. Membr. Sci. 2013, 446, 244-254.

(8) Saren, Q.; Qiu, C. Q.; Tang, C. Y. Synthesis and characterization of novel forward osmosis membranes based on layer-by-layer assembly. Environ. Sci. Technol. 2011, 45, 
(9) Song, X.; Wang, L.; Tang, C. Y.; Wang, Z.; Gao, C. Fabrication of carbon nanotubes incorporated double-skinned thin film nanocomposite membranes for enhanced separation performance and antifouling capability in forward osmosis process. Desalination 2015, 369, $1-9$.

(10) Xu, S.; Li, F.; Su, B.; Hu, M. Z.; Gao, X.; Gao, C. Novel graphene quantum dots (GQDs)-incorporated thin film composite (TFC) membranes for forward osmosis (FO) desalination. Desalination 2019, 451, 219-230.

(11) Zhao, X.; Liu, C. Efficient removal of heavy metal ions based on the selective hydrophilic channels. Chem. Eng. J. 2019, 359, 1644-1651.

(12) Bai, X.; Acharya, K. Removal of trimethoprim, sulfamethoxazole, and triclosan by the green alga nannochloris Sp. J. Hazard. Mater. 2016, 315, 70-75.

(13) Liu, P.; Zhang, H.; Feng, Y.; Shen, C.; Yang, F. Influence of spacer on rejection of trace antibiotics in wastewater during forward osmosis process. Desalination 2015, 371, 134-143. 